\title{
Crystal Violet Impregnated Slippery Surface to Prevent Bacterial Contamination of Surfaces
}

Adnan Patir ${ }^{\mathrm{a} t}$, Gi Byoung Hwang ${ }^{\mathrm{at}}$, Claudio Lourenco ${ }^{\mathrm{a}}$, Sean P Nair ${ }^{\mathrm{b}}$, Claire J. Carmalt ${ }^{\mathrm{a}}$ and Ivan P. Parkin ${ }^{\text {a* }}$

${ }^{a}$ Materials Chemistry Research Centre, Department of Chemistry, University College

London, 20 Gordon Street, London, WC1H OAJ, United Kingdom

${ }^{b}$ Department of Microbial Diseases, UCL Eastman Dental Institute, University College

London, Rowland Hill Street, London, NW3 2PF, United Kingdom

* To whom correspondence should be addressed.

E-mail: i.p.parkin@ucl.ac.uk Tel: 44(0)207 6794669 


\begin{abstract}
Biofilms which are self-organized communities can contaminate various infrastructural systems. Preventing bacterial adhesion on surfaces is more desirable than cleaning or disinfection of bacteria contaminated surfaces. In this study, a $24 \mathrm{~h}$ bacterial adhesion test showed that "slippery surfaces" had increased resistance to bacterial contamination compared to polydimethylsiloxane (PDMS) and superhydrophobic surfaces. However, it did not completely inhibit bacteria attachment indicating that it only retards surface contamination by bacteria. Hence, a strategy of killing bacteria with minimal bacterial adhesion was developed. A crystal violet impregnated slippery (CVIS) surface with bactericidal and slippery features was produced through a simple dipping process. The CVIS surface had a very smooth and lubricated surface that was highly repellent to water and blood contamination. Bactericidal tests against $E$. coli and $S$. aureus showed that the CVIS surface exhibited bactericidal activity in dark and also showed significantly enhanced bactericidal activity $(>3 \log$ reduction in bacteria number) in white light.
\end{abstract}

KEYWORDS: slippery surface, crystal violet, anti-biofouling, bacteria, reactive oxygen species 


\section{INTRODUCTION}

Bacteria commonly exist in nature and anthropogenic environments ${ }^{1-2}$. Bacteria form biofilms on surfaces in favourable environments ${ }^{1-2}$. Biofilms are resistant to various antimicrobial treatments and it is hard to remove biofilms adhered to surfaces ${ }^{3-6}$. Biofilms can contaminate various infrastructural systems and devices, for example, plumbing pipes, heating and air condition systems, food packing processes, and medical implants ${ }^{7-9}$. In hospital settings, biofilms persistently pose an infection threat. In $2016 / 17$, there were an estimated 834,000 incidents of healthcare associated infections (HAIs) among adult inpatients and healthcare professionals in the National Health Service (NHS) hospitals in England and it was estimated that 28,500 patients died ${ }^{10}$. Respiratory tract, urinary tract, surgical site and bloodstream infections which may be attributed to bacteria surface contamination accounted for $63 \%$ of all HAIs in England ${ }^{11}$.

Biofilms are a self-organized community, that have cooperative behaviour through cell to cell communications and other factors enabling enhanced metabolic diversity and effectiveness ${ }^{12-}$ 15. Bacterial cells in biofilms are covered and bound together by charged exopolysaccharide and proteins, which can prevent diffusion and penetration of antimicrobial agents into the biofilm, resulting in resistance to antimicrobial treatment ${ }^{12-15}$. For example, among the 312 hospital room surfaces tested, 83 rooms were still contaminated by vancomycin-resistant Enterococcus faecium after four cycles of routine cleaning and disinfection ${ }^{5}$. Pseudomonas pickettii and P. aeruginosa colonized on the interior of PVC pipes and survived for several days treatment of multiple disinfectants ${ }^{16}$.

Preventing bacterial adhesion on surfaces is more desirable than cleaning or disinfection of bacteria contaminated surfaces. Numerous techniques for preventing bacterial adhesion have been suggested. Most of the strategies have involved either bactericidal or anti-biofouling

surfaces ${ }^{17-19}$. Bactericidal surfaces release biocides into the surrounding environment and have 
been actively studied for example silver or copper nanoparticle coatings releasing metal ions, photocatalysts and graphene oxide coatings which produce reactive oxygen species ${ }^{20-27}$. Antibiofouling surfaces commonly use chemical functional groups to minimize biomolecule absorption or reduce the contact surface area between bacteria and the surface ${ }^{28}$. The antibiofouling of superhydrophobic and slippery surfaces has been extensively studied ${ }^{6,29-35}$. For superhydrophobic surfaces, it was reported that a bubble layer entrapped on the rough surface with low surface energy can decrease the contact area between the bacteria and the surface such that it was difficult for the air/water interface to be penetrated by planktonic bacteria resulting in low bacterial adhesion ${ }^{6}$. However, the anti-biofouling property of the surface was not maintained over a long period of time as the air bubbles typically dissolved in the solvents tested ${ }^{6}$. The anti-biofouling feature of a slippery surface is stronger and longer-lasting than that of the superhydrophobic surface and shows a good repellency to adherence for a range of organisms including mussels, bacteria, and algae $31,33,36$. It was reported that the lubricant oil layer which infused the solid surface prevented the organism from reaching the solid surface or that the lubricant surface deceives the sensing mechanism of the organisms which is initiated for adhesive behaviour ${ }^{31,33}$.

In this study, it was observed that slippery surfaces were more resistant to bacterial contamination than PDMS and superhydrophobic surfaces. However, the surface did not completely prevent bacterial adhesion, indicating that it retards surface contamination by bacteria. To obtain a surface capable of killing bacteria with minimization of bacterial adhesion, a crystal violet impregnated slippery (CVIS) surface was produced through a simple dipping process. Transmission electron and atomic force microscopies showed that CVIS surface formed a smooth and lubricant surface like slippery surface. It was observed that the CVIS surface was highly repellent to water and blood. In bactericidal testing against $S$. aureus and 
E. coli, the CVIS surface showed not only bactericidal activity in the dark but also significantly enhanced bactericidal activity in white light.

\section{EXPERIMENTAL SECTION}

\subsection{Sample Preparation}

2.1.1. PDMS Surface. 2 g of polydimethylsiloxane (PDMS, Dow Corning SYLGARD184, with $10 \%$ curing agent) was added in $20 \mathrm{~mL}$ of hexane and it was sonicated for $5 \mathrm{~min}$. Intact glass slides were dipped into the coating solution for $5 \mathrm{~s}$, and then, the slides were slowly withdrawn resulting in a formation of thin liquid film on the slide surface and they were dried for $1 \mathrm{~h}$ at room temperature. After the solvent was mostly evaporated, the sample was cured at $100{ }^{\circ} \mathrm{C}$ for $2 \mathrm{~h}$.

2.1.2. Superhydrophobic Surface. Superhydrophobic surfaces were produced by a dipcoating process. For coating solution, $2 \mathrm{~g}$ of PDMS containing $10 \%$ curing agent and $2.75 \mathrm{~g}$ of silicon dioxide $\left(\mathrm{SiO}_{2}\right)$ nanoparticles with a size of 5-15 nm were dispersed in $20 \mathrm{~mL}$ of hexane and it was sonicated for $5 \mathrm{~min}$. The intact glass slide was dipped into the coating solution for $5 \mathrm{~s}$, and then, the slide was slowly withdrawn resulting in a formation of thin liquid film on its surface and it was dried for $1 \mathrm{~h}$ at room temperature. After the solvent was mostly evaporated, the sample was cured at $100{ }^{\circ} \mathrm{C}$ for $2 \mathrm{~h}$.

2.1.3. Slippery Surface. The superhydrophobic surface was dipped into silicone oil and the surface was slowly withdrawn. The excessive oil was removed from the surface.

2.1.4. Crystal violet Impregnated Slippery (CVIS) Surface. Crystal violet solution was prepared at a concentration of $1000 \mathrm{ppm}$ in ethanol. The superhydrophobic surface was placed into $50 \mathrm{~mL}$ of the crystal violet dissolved in ethanol for $24 \mathrm{~h}$, and after that the surface was collected and dried in the dark. The superhydrophobic surface was dipped in silicone oil and then the excessive oil was removed from the slide surface. 
2.1.5. UV-Vis Absorbance Spectra and Light Transmission Rate of Treated Samples. To determine the UV-Vis absorbance spectra and light transmission rate of PDMS, superhydrophobic, slippery and CVIS surfaces, UV-Vis spectrometer (Lambda 25, PerkinElmer Inc., USA) was used and the spectra and transmission was measured over the wavelength range of $380-800 \mathrm{~nm}$.

2.2. Bactericidal Test. Escherichia. coli ATCC 25922 and Staphylococcus aureus 8325-4 were used in this study. E. coli and S. aureus were kept at $-70{ }^{\circ} \mathrm{C}$ in brain-heart-infusion broth (BHI broth, Oxoid Ltd., England, UK) containing 20\%(v/v) glycerol. E. coli and S. aureus were propagated on Macconkey (Oxoid Ltd.) and Manitol salt agar (Oxoid Ltd.), respectively. One bacterial colony of each bacterium was inoculated into $10 \mathrm{~mL}$ of BHI broth and incubated at $37{ }^{\circ} \mathrm{C}$ for $18 \mathrm{~h}$ with shaking at $200 \mathrm{rpm}$. After $18 \mathrm{~h}$ incubation, the bacteria were collected by centrifugation $\left(20^{\circ} \mathrm{C}, 5000 \mathrm{rpm}, 5 \mathrm{~min}\right)$, washed using $10 \mathrm{~mL}$ of phosphate buffered saline (PBS) and vortexed for 1 min to resuspend the suspension, and subsequently this process was repeated. The bacterial suspension was diluted 1000 -fold to obtain $\sim 10^{6} \mathrm{CFU} / \mathrm{mL}$. The treated samples were inoculated with $25 \mu \mathrm{L}$ of bacterial suspension and covered with a sterile cover slip $(18 \mathrm{~mm} \times 18 \mathrm{~mm})$ to achieve uniform distribution of bacteria and decent contact between sample surface and the bacteria. After that, the samples were placed into a petri dish with wet paper to keep constant humidity, and then illuminated by a white light source (28W white fluorescent lamp, GE Lighting, USA). The emission wavelength of the light source ranges from 400 to $730 \mathrm{~nm}^{37}$. Another set of samples were located into a dark room. The intensity of the white light source was $~ 6000$ lux on average. After the incubation in dark or white light, the samples were washed using $5 \mathrm{~mL}$ of PBS, the bacterial suspensions were plated on MacConkey agar for E. coli and mannitol salt agar for S. aureus and incubated for $24 \mathrm{~h}$ (E. coli) or $48 \mathrm{~h}$ ( $S$. aureus) at $37^{\circ} \mathrm{C}$, and then bacterial colonies which were grown were counted. 
2.3. Bacterial Adhesion. Bacterial suspensions with $\sim 10^{8} \mathrm{CFU} / \mathrm{mL}$ were used for bacteria adhesion. The treated samples were immersed and incubated in bacterial suspension for $24 \mathrm{~h}$ at $37^{\circ} \mathrm{C}$. After $24 \mathrm{~h}$, the samples were removed from the suspension, rinsed using DI water twice to eliminate weakly adhered bacteria, and placed into $0.1 \%$ crystal violet solution for 10 min to stain the bacteria adhered to samples. The samples were washed vigorously in DI water twice, placed into $10 \mathrm{~mL}$ of pure ethanol, vortexed to solubilize crystal violet for $3 \mathrm{~min}$. Residues in ethanol were removed through centrifugation for $1.5 \mathrm{~min}$ at $14000 \mathrm{rpm}$, and the absorbance of the solution was measured at $590 \mathrm{~nm}$ by UV-Vis spectrometer.

2.4. Bacterial Surface Coverage. The treated samples were immersed in bacterial suspension with $\sim 10^{8} \mathrm{CFU} / \mathrm{mL}$ for $24 \mathrm{~h}$ at $37{ }^{\circ} \mathrm{C}$. After that, the samples were washed using DI water twice, and placed into $0.1 \%$ crystal violet solution for $10 \mathrm{~min}$ to stain bacteria adhered to samples. The stained samples were washed using DI water and dried in dark. To determine bacteria surface coverage, the area stained by crystal violet was analyzed using ImageJ software.

Bacteria surface coverage was calculated as equation below

$$
\text { Bacteria surface coverage }(\%)=100 \times \frac{\text { bacteria surface coverage }}{\text { total area }}
$$

2.5. AFM and SEM Analyses. To measure the topography of the treated samples, Atomic force microscope (AFM) and scanning electron microscope (SEM, JEOL Inc., USA) were employed. Veeco AFM (Veeco Instruments Inc., USA) was used for slippery and CVIS surfaces, and Nanosurf AFM (Nanosurf AG, Switzerland) was used for superhydrophobic and PDMS surfaces. The AFMs employed a contact tapping mode. Ultra-thin film of gold was coated to sample surface through a sputter process and the images of samples were taken by SE, at an acceleration voltage of $5 \mathrm{kV}$.

2.6. Water Contact Angle. Water contact angles of the treated samples were measured using a water contact angle meter (First Ten Angstroms, Virginia, USA). A gauge 30 needle dispensed a 
droplet of water $(5.0 \mu \mathrm{L})$ by gravity and over 5 measurements were taken to measure the average contact angle for each sample. A contact angle of water droplet on the samples were photographed and analysed using Surftens 4.5 software.

For water repellent test on the treated samples, from a pipette, $0.5 \mathrm{~mL}$ of methylene blue dye dissolved water was dropped onto sample surface which was titled at an angle of $20^{\circ}$.

2.7. Contact Angle Hysteresis. Contact angle hysteresis of the treated samples was measured using an "add and remove volume" method ${ }^{38}$. The difference of advanced and receding angles against samples was calculated to get contact angle hysteresis.

2.8. Leaching test. To investigate CVIS stability, the treated sample $(75 \mathrm{~mm} \times 26 \mathrm{~mm})$ was immersed in $45 \mathrm{~mL}$ of DI water at normal temperature for 6 days. Absorbance of DI water at $590 \mathrm{~nm}$ was periodically measured using UV-Vis spectrometer if crystal violet molecules were leached from CVIS to DI water.

2.9. Blood Repellent Test. Blood repellency of the treated samples was tested using defibrinated horse blood (EO lab, Scotland, UK). The blood droplets were allowed to fall onto the treated surface which was tilted at $60^{\circ}$ and the surfaces were immersed into $20 \mathrm{~mL}$ of the blood for 5 min and withdrawn slowly from the solution to determine blood surface coverage. 


\section{RESULTS AND DISCUSSIONS}

In order to produce the CVIS surface, a superhydrophobic surface consisting of PDMS and $\mathrm{SiO}_{2}$ nanoparticles was produced by a simple dipping process and then crystal violet molecules were impregnated into the superhydrophobic surface through $24 \mathrm{~h}$ immersion in ethanol containing crystal violet. After that, silicone oil was infused into the surface (Scheme 1). As a comparison, PDMS, superhydrophobic and slippery surfaces were prepared. As shown in Figure 1 a). PDMS and slippery surfaces appear colourless and the colours of the superhydrophobic and CVIS surfaces were white and violet, respectively. Figure $1 \mathrm{~b}$ ) and Figure S1 show UV-Vis absorbance spectra and light transmission rate of the treated surfaces in the range of 380-800 nm. PDMS, superhydrophobic and slippery surfaces did not represent any notable absorption spectrum features over the range 380$800 \mathrm{~nm}$. However, the CVIS surface absorbed strongly at $590 \mathrm{~nm}$ due to the presence of crystal violet. Among the tested sample surfaces, the visible light transmission rate of PDMS surface was the highest and it showed a light transmission rate of $>90 \%$ over $380-800 \mathrm{~nm}$. The visible light transmission rate of superhydrophobic surface was $\sim 0.4 \%$, indicating the lowest transmission rate. The slippery surface resulted from silicone oil infusion into superhydrophobic presented a visible light transmission rate of $75-88 \%$. The silicone infusion led to enhanced visible light transmission of $>74.5 \%$. This is attributed to the enhanced transmission to the reduced refractive index contrast of the oil /air interface, compared to the original surface/air interface. Crystal violet impregnation into the slippery surface resulted in a significant reduction of the transmission rate. As a result, the rate of CVIS surface was $<22 \%$ over the range of $380-800 \mathrm{~nm}$.

Figure $1 \mathrm{c}$ ) shows coating thickness and topography of the PDMS, superhydrophobic, slippery and CVIS surfaces imaged by scanning electron microscopy (SEM). The PDMS surface was smooth. The superhydrophobic surface produced a rough topography with a coating thickness of $\sim 8.5 \mu \mathrm{m}$. This is because of coalescence of PDMS and $\mathrm{SiO}_{2}$ nanoparticles. Silicone oil infusion into the superhydrophobic surface formed a fluid-like layer on the rough surface, resulting in transformation 
from rough to smooth surface and after the oil infusion, the surface thickness increased to nearly double (Figure 1c)). Crystal violet impregnation into the slippery surface did not cause a change of the topography and coating thickness (Figure 1c)).

Table 1 shows a static water contact angle, contact angle hysteresis and surface roughness of PDMS, superhydrophobic, slippery and CVIS surfaces. All of tested surfaces were hydrophobic and the superhydrophobic surface had the highest water contact angle $\left(\sim 159.4^{\circ}\right)$ and surface roughness $\left(\mathrm{R}_{\mathrm{a}}\right.$, $\sim 1000 \mathrm{~nm})$. Slippery and CVIS surfaces had the lowest water contact angle $\left(\sim 103.5^{\circ}\right)$ and surface roughness $\left(\mathrm{R}_{\mathrm{a}}, \sim 0.6 \mathrm{~nm}\right)$. In terms of contact angle hysteresis, PDMS had the highest contact angle $\left(27.9^{\circ}\right)$ while the angle hysteresis of other samples was $<3^{\circ}$.

To determine the water repellency of the PDMS, superhydrophobic, slippery and CVIS surfaces, droplets of water stained with methylene blue were dropped onto the titled surfaces at distance of $5 \mathrm{~cm}$. Figure $\mathrm{S} 2$ shows the water repellency of the tested surfaces. The droplets were entrapped on PDMS whereas the droplets bounced and rolled off on the superhydrophobic surface and in the case of slippery and CVIS surfaces, the water droplets slid off the surfaces. Additionally, in a 5 min water dipping test, superhydrophobic, slippery and CVIS surfaces still kept their water repellent properties indicating that the surfaces were not wetted by water.

In the blood repellent test, blood droplets were allowed to fall onto the treated surface and the surfaces were then immersed into the blood for $5 \mathrm{~min}$. Contrary to water, blood is a nonNewtonian fluid which changes its viscosity under shear stress. As shown in Figure 2 a), droplets of the blood were allowed to fall on the surfaces which were tilted at $60^{\circ}$. The PDMS surface was instantly contaminated by the blood droplets. In the case of the superhydrophobic surfaces initially, the blood droplet rolled off on the surface, however after repeated blood dropping into it, the surface was contaminated. The blood droplets slid off on the slippery and CVIS surfaces without any blood contamination. As shown in Figure 2 b), 5 min blood dipping test showed that the 
superhydrophobic surface was totally contaminated by the blood whereas slippery and CVIS surfaces had only minor levels of contamination compared to that of the superhydrophobic surface. For the bacterial adhesion test against PDMS, superhydrophobic and slippery surfaces, all the surfaces were immersed horizontally in bacterial suspensions with $\sim 10^{8} \mathrm{CFU} / \mathrm{mL}$ in PBS and they were incubated for $24 \mathrm{~h}$ at $37^{\circ} \mathrm{C}$. After that, bacteria attached to the surfaces were stained by $0.1 \%$ crystal violet $(\mathrm{CV})$ solution. Figure 3 a) shows bacterial surface coverage against PDMS, superhydrophobic and slippery surfaces. After $24 \mathrm{~h}$ bacterial exposure, 95.6 and $91.7 \%$ of superhydrophobic surfaces were colonized by S. aureus and E. coli, respectively. 18.2 and $13.2 \%$ of the PDMS surfaces were covered by S. aureus and E. coli, respectively. In the case of slippery surfaces, the coverage by both bacteria was $<5 \%$. For quantitative comparison of attached bacteria, the stained surfaces were immersed into $10 \mathrm{~mL}$ of pure ethanol and the crystal violet leached out from the bacterial membranes to ethanol were measured at $590 \mathrm{~nm}$ using a UV-Vis spectrometer. As shown in Figure $3 \mathrm{~b}$ ), the superhydrophobic surface showed the highest bacterial adhesion among the tested samples. Compared to superhydrophobic surface, S. aureus and E. coli adhesions of PDMS were 79.8 and 91.1\% lower, respectively. The adhesion of both bacteria to the slippery surface was $~ 98 \%$ lower than that of a superhydrophobic surface. To determine the factors that contribute to an increase of bacterial adhesion, the surfaces were analysed in terms of surface roughness. As shown in Figure $3 \mathrm{c}$ ), there was a statistically significant correlation between bacterial adhesion and the surface roughness of the sample surfaces (Pearson correlation coefficient (PCC): $r>0.99$ ). This indicates that compared to the smooth surface, it was relatively easy for bacteria to adhere on a rough surface. Thus, it can be explained that the high roughness of the superhydrophobic surface provided a favourable environment where bacteria adhered whereas the smooth surface that resulted from silicone oil infusion into the superhydrophobic surface makes bacteria less adhesive. Additionally, the thin silicone oil layer on slippery surface may interfere with 
bacteria adhesion to the surface. Although a slippery surface was not able to completely prevent bacterial adhesion, it could retard bacterial film formation. Bacterial adhesion to the CVIS surface was not tested because it was not possible to determine bacteria attached to CVIS surface using $0.1 \%$ crystal violet stain. However, it is expected that bacterial repulsion from the CVIS surface is similar to that of the slippery surface.

For bactericidal tests, $25 \mu \mathrm{L}$ of bacterial suspensions ranging from 1.3 to $4.6 \times 10^{6} \mathrm{CFU} / \mathrm{mL}$ were inoculated onto the treated surfaces. The surface was then exposed to white light with intensity of 6000 lux or incubated in a dark room at $20^{\circ} \mathrm{C}$ for same period of time. Figure 4 shows the bactericidal activity of slippery and CVIS surfaces against E. coli and S. aureus in the dark and on exposure to white light. The slippery surface did not show any bactericidal activity in the dark nor on exposure to white light (P-value > 0.1). The CVIS surface showed bactericidal activities against E. coli and S. aureus in dark and white light. After $3 \mathrm{~h}$ incubation in the dark, a reduction in the number of E. coli was $0.72 \log$ on CVIS, compared to slippery surface $(\mathrm{P}$-value $<0.05)$ and the number reduction of $S$. aureus was $0.54 \log$ after $2 \mathrm{~h}$ incubation in dark (P-value $<0.01$ ). Crystal violet has been extensively used to prevent viral, bacterial and fungal infections in medicine for over 100 years $^{39}$. It has been known that crystal violet inhibits bacterial growth through an interaction between positive ion $\left(\mathrm{CV}^{+}\right)$dissociated from crystal violet and bacterial membrane or DNA ${ }^{39-40}$. Bactericidal activity of CVIS in dark indicates that crystal violet maintains some intrinsic bactericidal activity after impregnation into slippery surface. In white light, the reductions in the number of $E$. coli and $S$. aureus reached to below the detection limit $\left(\sim 10^{3} \mathrm{CFU} / \mathrm{mL}\right)$ after $3 \mathrm{~h}$ and $2 \mathrm{~h}$ incubations, respectively indicating $>3 \mathrm{log}$ reduction in the number of bacteria $(99.9 \%$ kill). The potent bactericidal activity of the CVIS surface in white light can be explained as follows: when crystal violet is exposed to a light, the crystal violet dye transforms into a triplet state via an excited single state $e^{41-45}$. The triplet state of crystal violet induces reactive oxygen species (ROS) formation through photochemical 
pathway-I and II. The induced ROS attacks the bacteria at multiple sites resulting in bacterial death $^{41-45}$.

To determine CVIS stability, the sample was immersed in DI water and absorbance of DI water at $590 \mathrm{~nm}$ was periodically measured for 6 days. As shown Figure 5, after $24 \mathrm{~h}$ immersion, a minor leaching $(0.063 \mathrm{ppm})$ of crystal violet was detected and any additional leaching was not observed after that. Over a period of 6 days, the total amount of crystal violet leached out from CVIS was $<0.01 \%$

A major source of surface contamination would occur from an absorbance of liquid-borne contaminants by solid surface in contact with the liquid ${ }^{1-2,4}$. The liquid-borne contaminants including bacteria, virus, protein and others organic substances not only stain surfaces but also produce a major source of hospital associated infections by seeding formation for biofilms ${ }^{1-2}$, ${ }^{4}$. Previous studies showed that superhydrophobic surfaces minimises the direct contact between the solid surface and the liquid-borne bacteria by the water repellent feature and air bubbles entrapped to the surfaces, resulting in a significant reduction of bacteria adhesion ${ }^{6,46}$. However, in a prolonged exposure to the liquid, the superhydrophobic surface causes relatively high bacterial adhesion compared to other surfaces because of the air bubble loss and high surface roughness (Figure 3) ${ }^{6,46}$. Figure 2 shows that the surface was vulnerable to blood contamination indicating that the surface can be readily contaminated by other types of fluidborne contaminants. In the case of the slippery surface, despite its high resistance to liquid contamination, a small amount of bacterial adhesion was still observed, indicating that such surfaces can be a seeding base for formation of a biofilm. Thus, having both anti-biofouling and bactericidal properties would be beneficial to prevent biofilm formation on the surface. The CVIS surface developed in this study not only showed the fluid repellent features of the slippery surface, but also potent photobactericidal activity with $>3 \log$ reduction in the number of viable bacteria. It is expected that CVIS surface minimizes bacterial adhesion and then kills 
the residual small number of bacteria that adhere to the surface resulting in prevention of biofilm formation.

\section{CONCLUSION}

In this study, crystal violet impregnated slippery (CVIS) surfaces with bactericidal and slippery properties were produced through a simple dipping process. The CVIS surface gave a water contact angle of $103^{\circ}$ indicating hydrophobicity. It was observed that the CVIS surface was very smooth and had lubricant properties and that it was highly repellent to water and blood contamination. In bactericidal tests against $E$. coli and $S$. aureus, the CVIS surface exhibited not only bactericidal activity under dark condition but also potent photobactericidal activity in white light. It is expected that CVIS surface could be applied to biomedical and industrial spaces to prevent bacterial contamination of surfaces. 


\section{ASSOCIATED CONTENT}

\section{Supporting Information}

The Supporting Information is available free of charge

Light transmission rate of treated samples in a wavelength of 380-800 $\mathrm{nm}$, water repellent test of treated samples at a tilt angle of $20^{\circ}$

\section{AUTHOR INFORMATION}

\section{Corresponding Authors}

Ivan P. Parkin - Materials Chemistry Research Centre, Department of Chemistry, University College London, 20 Gordon Street, London, WC1H 0AJ, United Kingdom; E-mail: i.p.parkin@ucl.ac.uk

\section{Other Authors}

Adnan Patir - Materials Chemistry Research Centre, Department of Chemistry, University College London, 20 Gordon Street, London, WC1H OAJ, United Kingdom.

Gi Byoung Hwang - Materials Chemistry Research Centre, Department of Chemistry, University College London, 20 Gordon Street, London, WC1H OAJ, United Kingdom.

Sean P Nair - Department of Microbial Diseases, UCL Eastman Dental Institute, Royal Free Campus, University College London, London NW3 2PF, United Kingdom.

Claire J. Carmalt - Materials Chemistry Research Centre, Department of Chemistry, University College London, 20 Gordon Street, London, WC1H OAJ, United Kingdom.

\section{Author Contributions}

The manuscript was written through contributions of all authors. All authors have given approval to the final version of the manuscript.

\section{Conflict of interest}

The authors declare no competing financial interest.

\section{口ABBREVIATIONS}

CVIS, crystal violet impregnated slippery

PDMS, polydimethylsiloxane

ROS, reactive oxygen species

SEM, scanning electron microscopy 
Table 1. Water contact angle of PDMS, superhydrophobic, slippery and crystal violet impregnated slippery (CVIS) surfaces.

\begin{tabular}{cccc}
\hline Sample & $\begin{array}{c}\text { Water contact } \\
\operatorname{angle}\left({ }^{\circ}\right)\end{array}$ & $\begin{array}{c}\text { Contact angle } \\
\text { hysteresis }\left({ }^{\circ}\right)\end{array}$ & $\begin{array}{c}\text { Surface roughness } \\
\left(\mathrm{R}_{\mathrm{a}}, \mathrm{nm}\right)\end{array}$ \\
\hline PDMS surface & $111.6 \pm 3.3$ & $27.9 \pm 19.9$ & $61.9 \pm 49.3$ \\
$\begin{array}{c}\text { Superhydrophobic } \\
\text { surface }\end{array}$ & $159.4 \pm 1.1$ & $0.6 \pm 0.3$ & $1005.3 \pm 250.1$ \\
Slippery surface & $107.1 \pm 6.9$ & $1.4 \pm 1.1$ & $0.6 \pm 0.5$ \\
CVIS surface & $103.5 \pm 1.3$ & $2.4 \pm 1.6$ & $0.6 \pm 0.3$ \\
\hline
\end{tabular}




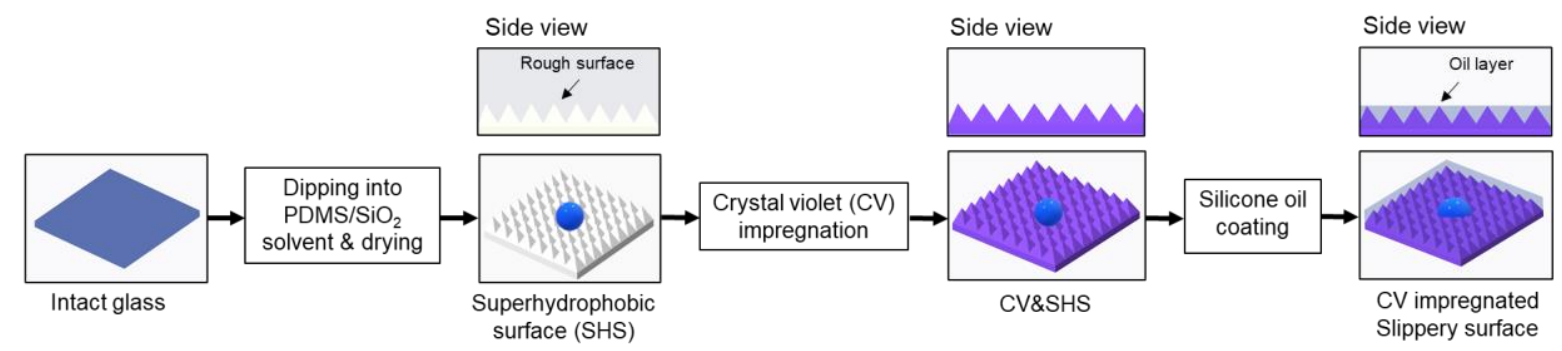

Scheme 1. Schematic diagram for preparation of crystal violet impregnated slippery (CVIS) surface 
a)

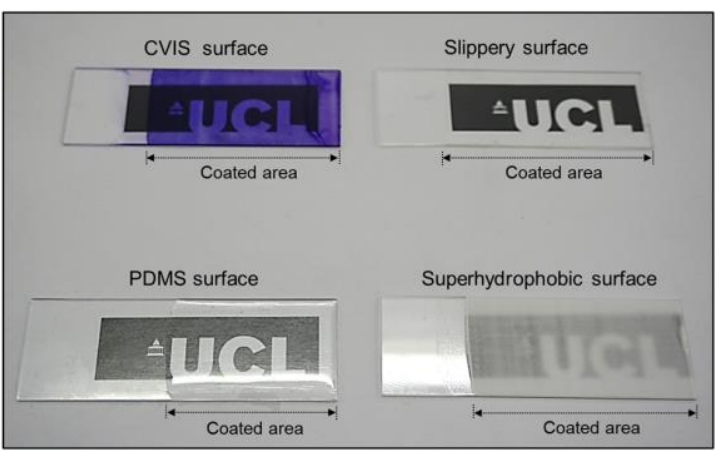

c)

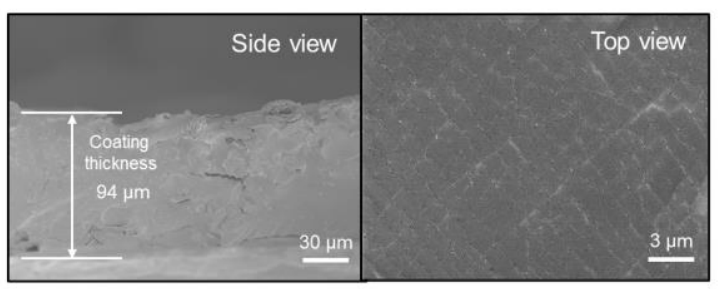

PDMS surface

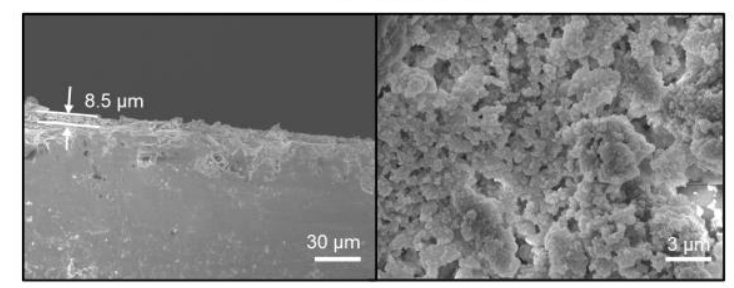

Superhydrophobic surface
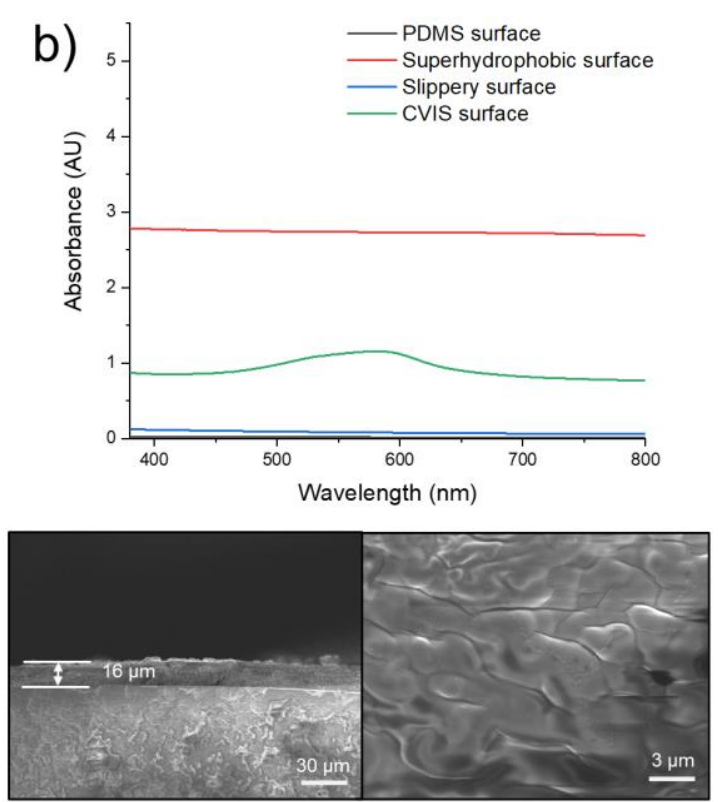

Slippery surface

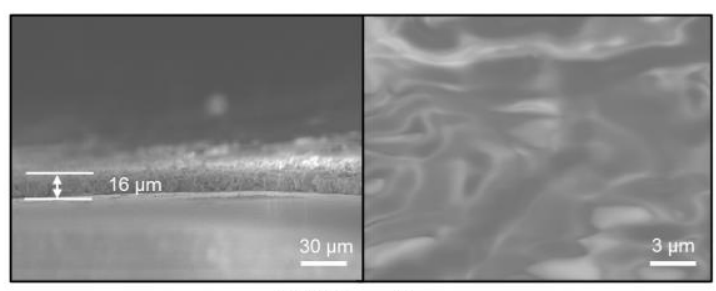

CVIS surface

Figure 1. a) Images, b) UV-Vis absorbance spectra, and c) SEM images of PDMS, superhydrophobic, slippery, and crystal violet impregnated slippery (CVIS) surfaces 

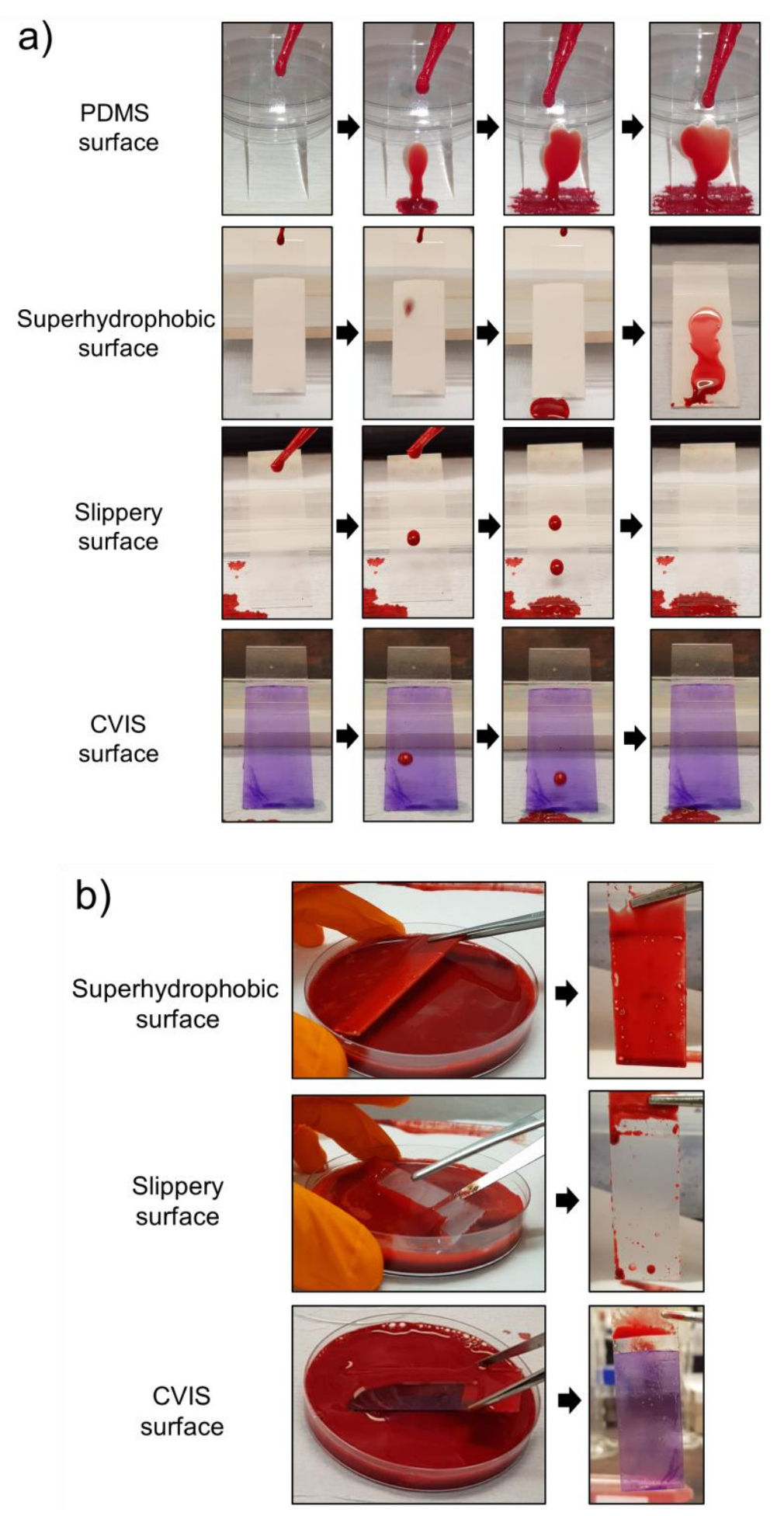

Figure 2. a) Blood repellent test of PDMS, superhydrophobic, slippery and crystal violet impregnated slippery (CVIS) surfaces at a tilted angle of $60^{\circ}$ and b) 5 min immersion of superhydrophobic, slippery and CVIS surfaces into blood 

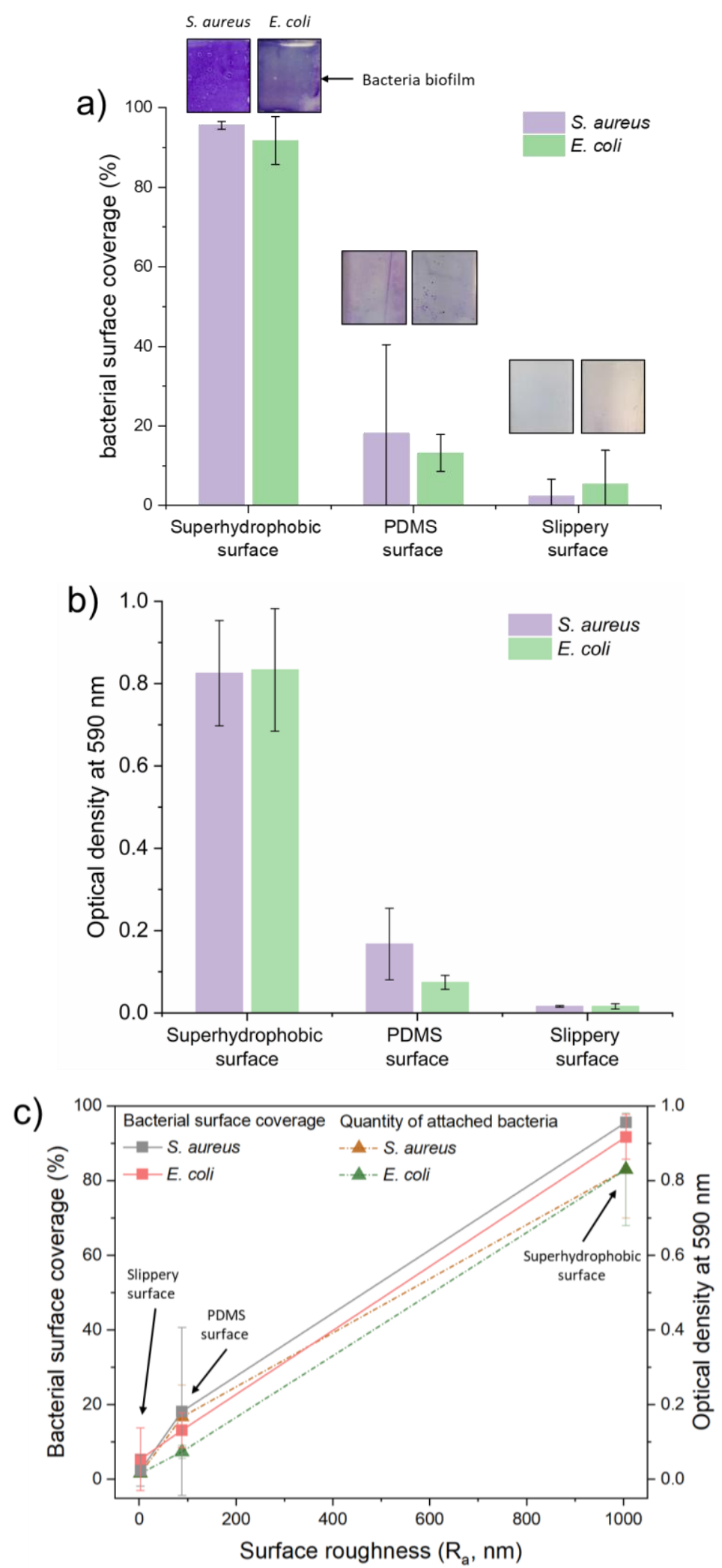

Figure 3. a) Total bacterial surface coverage and b) quantity of attached bacteria on superhydrophobic, PDMS, and slippery surfaces. c) correlation between surface roughness and bacterial surface coverage or quantity of attached bacteria of superhydrophobic, PDMS and slippery surfaces. 


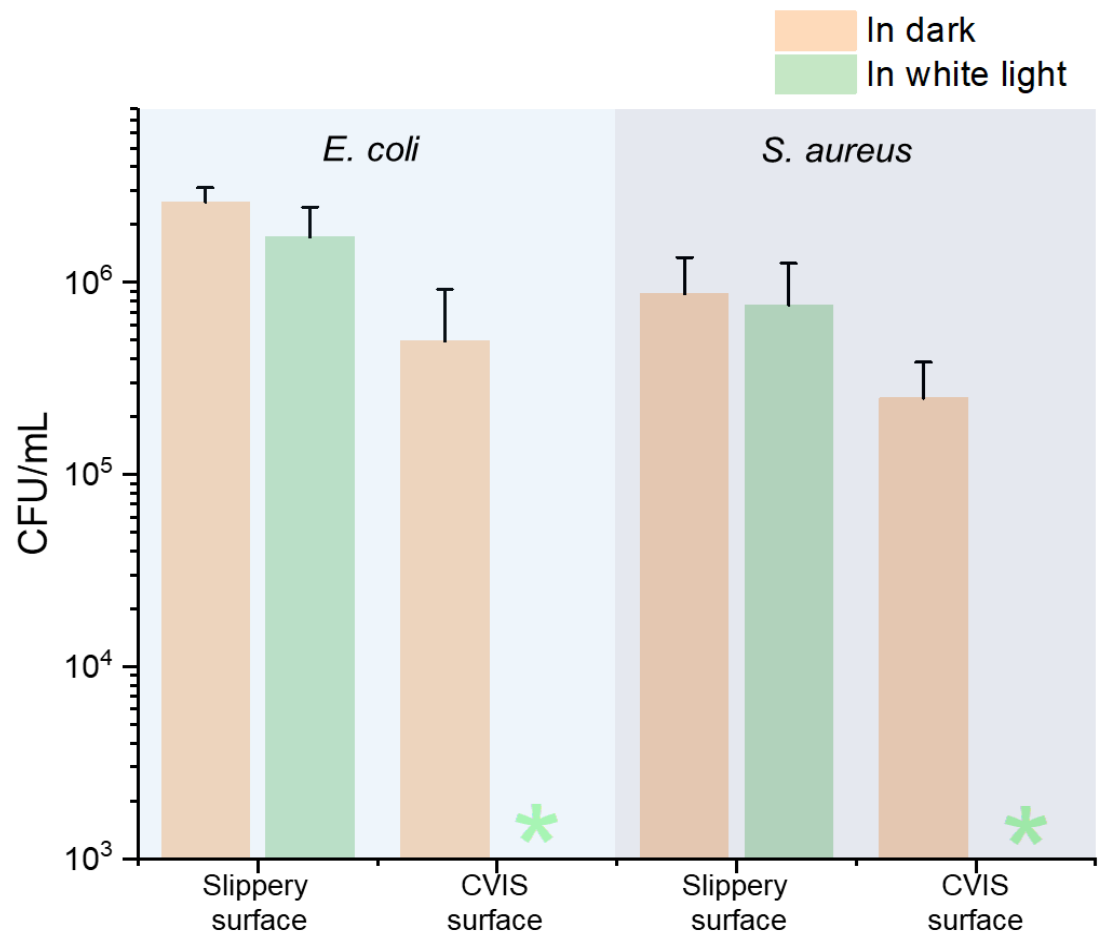

Figure 4. Bactericidal activity of slippery and crystal violet impregnated slippery (CVIS) surfaces against $E$. coli (incubation time: $3 \mathrm{~h}$ ) and $S$. aureus (incubation time: $2 \mathrm{~h}$ ) in dark and white light. All experiments were performed at $20^{\circ} \mathrm{C}$. The intensity of white light was $\sim 6000$ lux in average.

$*$ below detection limit $\left(<10^{3} \mathrm{CFU} / \mathrm{mL}\right)$ 


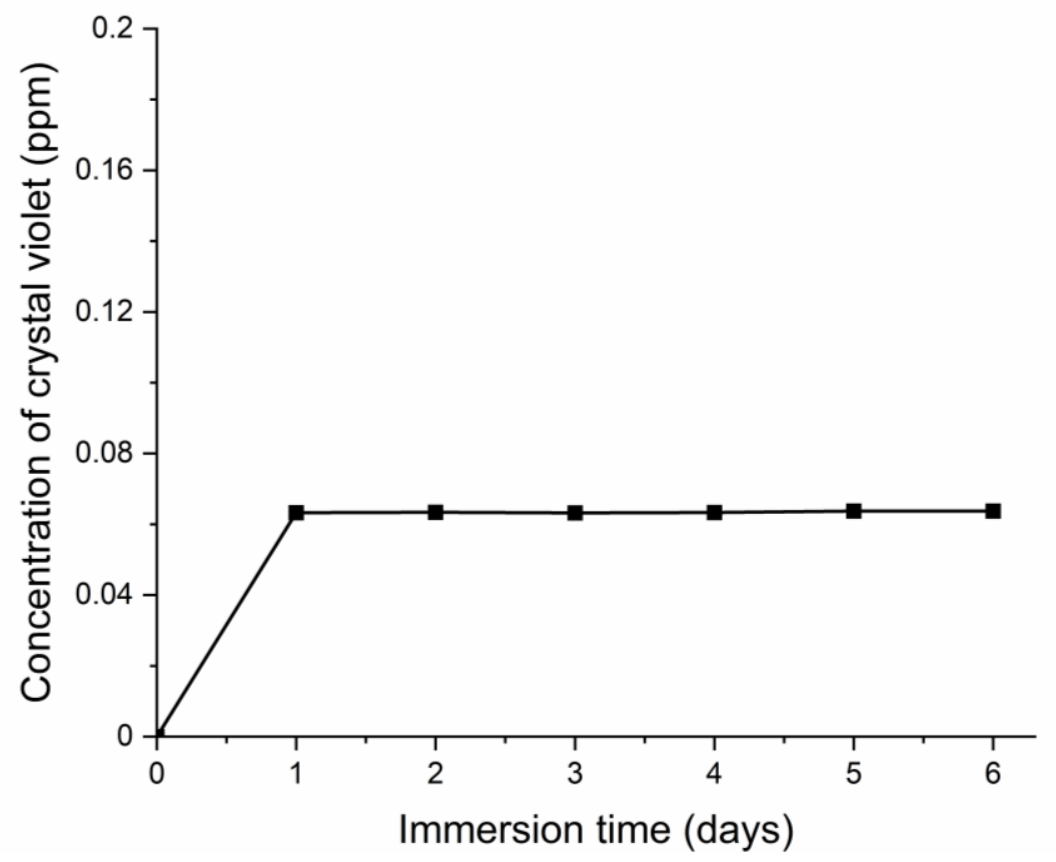

Figure 5. Leaching of crystal violet from crystal violet impregnated slippery (CVIS) surface. CVIS was immersed for 6 days and concentration of crystal violet leached out from the sample to DI water was measured at $590 \mathrm{~nm}$ using UV-Vis spectrometry 


\section{References}

(1) Shapiro, J. A. Thinking about Bacterial Populations as Multicellular Organisms. Annu. Rev. Microbiol. 1998, 52, 81-104.

(2) Wilking, J. N.; Angelini, T. E.; Seminara, A.; Brenner, M. P.; Weitz, D. A. Biofilms as Complex Fluids. MRS Bulletin 2011, 36, 385-391.

(3) Davies, D. Understanding Biofilm Resistance to Antibacterial Agents. Nat. Rev Drug. Discov. 2003, 2, 114-122.

(4) Hayden, M. K.; Blom, D. W.; Lyle, E. A.; Moore, C. G.; Weinstein, R. A. Risk of Hand or Glove Contamination after Contact with Patients Colonized with Vancomycin-Resistant Enterococcus or the Colonized Patients' Environment. Infect. Control Hosp. Epidemiol. 2008, 29, 149-154.

(5) Byers, K. E.; Durbin, L. J.; Simonton, B. M.; Anglim, A. M.; Adal, K. A.; Farr, B. M. Disinfection of Hospital Rooms Contaminated with Vancomycin-Resistant Enterococcus Faecium. Infect. Control Hosp. Epidemiol. 1998, 19, 261-264.

(6) Hwang, G. B.; Page, K.; Patir, A.; Nair, S. P.; Allan, E.; Parkin, I. P. The Anti-Biofouling Properties of Superhydrophobic Surfaces are Short-Lived. ACS Nano 2018, 12, 6050-6058.

(7) Costerton, J. W.; Stewart, P. S. Battling Biofilms. Sci. Am. 2001, 285, 74-81.

(8) Kumar, C. G.; Anand, S. K. Significance of Microbial Biofilms in Food Industry: a Review. Int. J. Food Microbiol. 1998, 42, 9-27.

(9) Chmielewski, R. A. N.; Frank, J. F. Biofilm Formation and Control in Food Processing Facilities. Compr. Rev. Food Sci. Food Saf. 2003, 2, 22-32.

(10) Guest, J. F.; Keating, T.; Gould, D.; Wigglesworth, N. Modelling the Annual NHS Costs and Outcomes Attributable to Healthcare-Associated Infections in England. BMJ Open 2020, 10, $\mathrm{e} 033367$.

(11) Health Protection Agency, English National Point Prevalence Survey on HealthcareAssociated Infections and Antimicrobial Use.

https://webarchive.nationalarchives.gov.uk/20140714085429/http://www.hpa.org.uk/Publicat ions/InfectiousDiseases/AntimicrobialAndHealthcareAssociatedInfections/1205HCAIEnglish PPSforhcaiandamu2011prelim/.

(12) Vlamakis, H.; Aguilar, C.; Losick, R.; Kolter, R. Control of Cell Fate by the Formation of an Architecturally Complex Bacterial Community. Genes Dev. 2008, 22, 945-953.

(13) Stewart, P. S.; Franklin, M. J. Physiological Heterogeneity in Biofilms. Nat. Rev. Microbiol. 2008, 6, 199-210.

(14) Klausen, M.; Aaes-Jorgensen, A.; Molin, S.; Tolker-Nielsen, T. Involvement of Bacterial Migration in the Development of Complex Multicellular Structures in Pseudomonas Aeruginosa Biofilms. Mol. Microbiol. 2003, 50, 61-68.

(15) Ben-Jacob, E.; Cohen, I.; Gutnick, D. L. Cooperative Organization of Bacterial Colonies: from Genotype to Morphotype. Annu. Rev. Microbiol. 1998, 52, 779-806.

(16) Anderson, R. L.; Holland, B. W.; Carr, J. K.; Bond, W. W.; Favero, M. S. Effect of Disinfectants on Pseudomonads Colonized on the Interior Surface of PVC Pipes. Am. J.

Public Health 1990, 80, 17-21.

(17) Genzer, J.; Efimenko, K. Recent Developments in Superhydrophobic Surfaces and their Relevance to Marine Fouling: a Review. Biofouling 2006, 22, 339-360.

(18) Meyer, B. Approaches to Prevention, Removal and Killing of Biofilms. Int. Biodeterior. Biodegradation 2003, 51, 249-253.

(19) Cloutier, M.; Mantovani, D.; Rosei, F. Antibacterial Coatings: Challenges, Perspectives, and Opportunities. Trends Biotechnol. 2015, 33, 637-652.

(20) Kumar, P.; Huo, P.; Zhang, R.; Liu, B. Antibacterial Properties of Graphene-Based Nanomaterials. Nanomaterials 2019, 9, 737. 
(21) Patir, A.; Hwang, G. B.; Nair, S. P.; Allan, E.; Parkin, I. P. Photobactericidal Activity of Dual Dyes Encapsulated in Silicone Enhanced by Silver Nanoparticles. ACS Omega 2018, 3, 6779-6786.

(22) Zheng, K.; Setyawati, M. I.; Leong, D. T.; Xie, J. Antimicrobial Gold Nanoclusters. ACS Nano 2017, 11, 6904-6910.

(23) Sirelkhatim, A.; Mahmud, S.; Seeni, A.; Kaus, N. H. M.; Ann, L. C.; Bakhori, S. K. M.; Hasan, H.; Mohamad, D. Review on Zinc Oxide Nanoparticles: Antibacterial Activity and Toxicity Mechanism. Nano-Micro Lett. 2015, 7, 219-242.

(24) Hwang, G. B.; Noimark, S.; Page, K.; Sehmi, S.; Macrobert, A. J.; Allan, E.; Parkin, I. P. White Light-Activated Antimicrobial Surfaces: Effect of Nanoparticles Type on Activity. J. Mater. Chem. B 2016, 4, 2199-2207.

(25) Sehmi, S. K.; Noimark, S.; Weiner, J.; Allan, E.; MacRobert, A. J.; Parkin, I. P. Potent Antibacterial Activity of Copper Embedded into Silicone and Polyurethane. ACS Appl. Mater. Interfaces. 2015, 7, 22807-22813.

(26) Zhao, L.; Chu, P. K.; Zhang, Y.; Wu, Z. Antibacterial Coatings on Titanium Implants. J. Biomed. Mater. Res. 2009, 91, 470-480.

(27) Landsdown, A. B. G. Silver I: Its Antibacterial Properties and Mechanism of Action. J. Wound Care 2002, 11, 125-138.

(28) Banerjee, I.; Pangule, R. C.; Kane, R. S. Antifouling Coatings: Recent Developments in the Design of Surfaces that Prevent Fouling by Proteins, Bacteria, and Marine Organisms.

Adv. Mater. 2011, 23, 690-718.

(29) Freschauf, L. R.; McLane, J.; Sharma, H.; Khine, M. Shrink-Induced Superhydrophobic and Antibacterial Surfaces in Consumer Plastics. PLoS One 2012, 7, e40987.

(30) Crick, C. R.; Ismail, S.; Pratten, J.; Parkin, I. P. An Investigation into Bacterial Attachment to an Elastomeric Superhydrophobic Surface Prepared via Aerosol Assisted Deposition. Thin Solid Films 2011, 519, 3722-3727.

(31) Epstein, A. K.; Wong, T. S.; Belisle, R. A.; Boggs, E. M.; Aizenberg, J. Liquid-Infused Structured Surfaces with Exceptional Anti-Biofouling Performance. PNAS 2012, 109, 13182 13187.

(32) Privett, B. J.; Youn, J.; Hong, S. A.; Lee, J.; Han, J.; Shin, J. H.; Schoenfisch, M. H. Antibacterial Fluorinated Silica Colloid Superhydrophobic Surfaces. Langmuir 2011, 27, 9597-9601.

(33) Amini, S.; Kolle, S.; Petrone, L.; Ahanotu, O.; Sunny, S.; Sutanto, C. N.; Hoon, S.; Cohen, L.; Weaver, J. C.; Aizenberg, J.; Vogel, N.; Miserez, A. Preventing Mussel Adhesion using Lubricant-Infused Materials. Science 2017, 357, 668-673.

(34) Kovalenko, Y.; Sotiri, I.; Timonen, J. V. I.; Overton, J. C.; Holmes, G.; Aizenberg, J.; Howell, C. Bacterial Interactions with Immobilized Liquid Layers. Adv. Healthc. Mater. 2017, 6, 1600948.

(35) MacCallum, N.; Howell, C.; Kim, P.; Sun, D.; Friedlander, R.; Ranisau, J.; Ahanotu, O.; Lin, J. J.; Vena, A.; Hatton, B.; Wong, T.-S.; Aizenberg, J. Liquid-Infused Silicone as a Biofouling-Free Medical Material. ACS Biomater. Sci. Eng. 2014, 1, 43-51.

(36) Howell, C.; Vu, T. L.; Lin, J. J.; Kolle, S.; Juthani, N.; Watson, E.; Weaver, J. C.; Alvarenga, J.; Aizenberg, J. Self-Replenishing Vascularized Fouling-Release Surfaces. ACS Appl. Mater. Interfaces 2014, 6, 13299-13307.

(37) GE Lighting, 28 W white fluorescent lamp Data sheet. Jan. 2009.

(38) Hong, S.-J.; Li, Y.-F.; Hsiao, M.-J.; Sheng, Y.-J.; Tsao, H.-K. Anomalous Wetting on a Superhydrophobic Graphite Surface. Appl. Phys. Lett. 2012, 100, 121601.

(39) Dragan, J.; Michalak, S. Gentian Violet: What We Know and What Is Ahead of Us. Acta Pol. Pharm. 2019, 76 (3), 389-396. 
(40) Tatu, A. L.; Ardeleanu, V.; Elisei, A. M.; Dumitriu Buzia, O.; Miulescu, M.; Nwabudike, L. C. Undesirable Effects of Some Topical Antiseptics Chemical, Pharmacological and Dermatological Aspects. Revista. de Chimie. 2019, 70 (6), 2276-2281. (41) Docampo, R.; Moreno, S. N.; Muniz, R. P.; Cruz, F. S.; Mason, R. P. Light-Enhanced Free Radical Formation and Trypanocidal Action of Gentian Violet (crystal violet). Science 1983, 220, 1292-1295.

(42) Wainwright, M. Photodynamic Antimicrobial Chemotherapy (PACT). J. Antimicrob. Chemother. 1998, 42, 13-28.

(43) Henderson, B. W.; Dougherty, T. J. How Does Photodynamic Therapy Work? Photochem. Photobiol. 1992, 55, 145-157.

(44) Vatansever, F.; de Melo, W. C.; Avci, P.; Vecchio, D.; Sadasivam, M.; Gupta, A.; Chandran, R.; Karimi, M.; Parizotto, N. A.; Yin, R.; Tegos, G. P.; Hamblin, M. R.

Antimicrobial Strategies Centered Around Reactive Oxygen Species-Bactericidal Antibiotics, Photodynamic Therapy, and Beyond. FEMS Microbiol. Rev. 2013, 37, 955-989.

(45) Noimark, S.; Salvadori, E.; Gomez-Bombarelli, R.; MacRobert, A. J.; Parkin, I. P.; Kay, C. W. Comparative Study of Singlet Oxygen Production by Photosensitiser Dyes

Encapsulated in Silicone: Towards Rational Design of Anti-Microbial Surfaces. Phys. Chem. Chem. Phys. 2016, 18, 28101-28109.

(46) Truong, V. K.; Webb, H. K.; Fadeeva, E.; Chichkov, B. N.; Wu, A. H.; Lamb, R.; Wang, J. Y.; Crawford, R. J.; Ivanova, E. P. Air-Directed Attachment of Coccoid Bacteria to the Surface of Superhydrophobic Lotus-like Titanium. Biofouling 2012, 28 (6), 539-50. 
Table of Contents (TOC)/Abstract Graphic

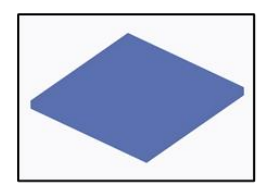

Intact glass

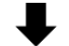

Dipping into $\mathrm{PDMS} / \mathrm{SiO}_{2}$ solvent \& drying

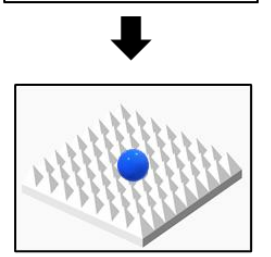

Superhydrophobic surface (SHS)

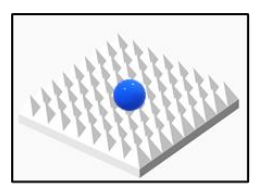

SHS

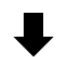

Crystal violet (CV) impregnation

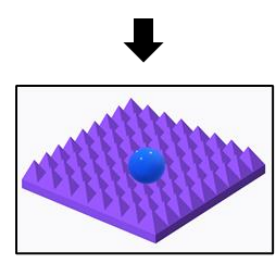

CV\&SHS

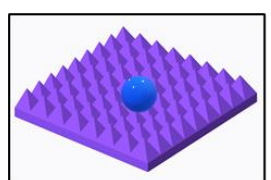

CV\&SHS

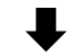

Silicone oil coating

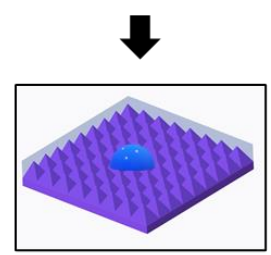

CV impregnated Slippery surface 